\title{
PERFORMANCE OF A PADC PERSONAL NEUTRON DOSEMETER AT SIMULATED AND REAL WORKPLACE FIELDS OF THE NUCLEAR INDUSTRY
}

\author{
A. Fiechtner*, M. Boschung and C. Wernli \\ Paul Scherrer Institute, CH-5232 Villigen PSI, Switzerland
}

\begin{abstract}
In the framework of the EVIDOS (Evaluation of Individual Dosimetry in Mixed Neutron and Photon Radiation Fields) project, funded by the EC, measurements with PADC personal neutron dosemeters were carried out at several workplace fields of the nuclear industry and at simulated workplace fields. The measured personal neutron dose equivalents of the PADC personal neutron dosemeter are compared with values that were assessed within the EVIDOS project by other partners. The detection limits for different spectra types are given. In cases were the neutron dose was too low to be measured by the PADC personal neutron dosemeter, the response is estimated by convoluting the responses to monoenergetic neutrons with the dose energy distribution measured within EVIDOS. The advantages and limitations of the PADC personal neutron dosemeter are discussed.
\end{abstract}

\section{INTRODUCTION}

The personal neutron dosimetry system at the Paul Scherrer Institute (PSI) is based on chemically etched CR-39 detectors and an automatic readout system. The neutron dosemeter is used for the measurement of thermal and high-energy neutrons (above $\sim 200 \mathrm{keV}$ ). The main application of this dosimetry system is individual neutron monitoring in accelerator fields, but it is also used in nuclear power plants.

Within the project EVIDOS $^{(1)}$ (Evaluation of Individual Dosimetry in Mixed Neutron and Photon Radiation Fields), which was funded by the EC within the fifth framework programme, measurement campaigns at real workplaces in the nuclear industry and at simulated workplace fields were performed.

The results are presented, and the advantages and limitations of the PADC personal neutron dosemeter are discussed.

\section{PERSONAL NEUTRON DOSIMETRY SYSTEM}

The detectors are made of CR-39 and were processed in a two-step chemical etching process ${ }^{(2)}$.

Each detector is covered by a $2 \mathrm{~mm}$ thick radiator on both sides. The radiators are divided into two parts: pure polyethylene (PE) for the measurement of high-energy neutrons and PE containing $1 \%$ of lithium of natural abundance (PE(Li)) for the measurement of thermal neutrons ${ }^{(2)}$. The neutron energy dependence of the response was measured ${ }^{(3)}$ and calculated and is shown in Figure 1. The responses to intermediate neutron energies were calculated by means of albedo spectra ${ }^{(4)}$ and the cross sections of natural abundance lithium ${ }^{(5)}$.

*Corresponding author: annette.fiechtner@psi.ch

\section{DESCRIPTION OF WORKPLACE FIELDS}

Two simulated work place fields were supplied by IRSN (Cadarache, France). These fields presented, respectively, a broad, partly thermalised spectrum, 'Canel'(6), and a highly thermalised spectrum, 'Sigma' ${ }^{\text {(7)' }}$.

Measurements at workplace fields of the nuclear industry were performed at the following locations and measurement positions:

At a boiling water reactor (BWR SAR and BWR T) and at a transport cask with used fuel elements (Cask NTL M and Cask NTL S) at the nuclear power plant in Krümmel, Germany.

At the MOX fuel processing plant Belgonucleaire (BN 1, BN 2A, BN 2B and BN 3), Belgium and at the research reactor VENUS at $\mathrm{CEN} \bullet \mathrm{SCK}$ (VENUS F and VENUS C), Belgium.

At a pressurised water reactor (PWR A and PWR

L) and at a transport cask with used fuel elements (Cask TN D and Cask TN N) at the nuclear power plant in Ringhals, Sweden.

At a European nuclear facility (NF 1 and NF 2).

In Figure 2 typical schematic relative dose distributions are shown for spectra of reactors, of the VENUS reactor, of transport casks and of MOX fuel processing, respectively of the nuclear facility. All measurement positions and neutron spectra are described more detailed elsewhere ${ }^{(8)}$.

\section{RESULTS}

For the irradiations, the dosemeters were mounted on a Perspex-slab-phantom of size $30 \times 30 \times$ $15 \mathrm{~cm}^{3}$. The front surface of the slab-phantom was aligned to a direction specified to be $0^{\circ}$. 


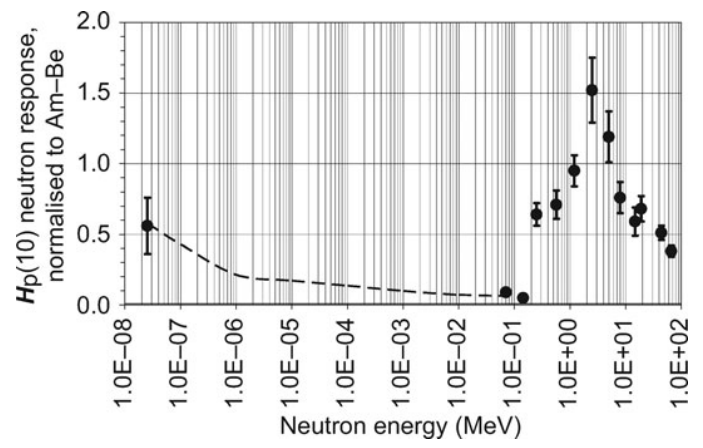

Figure 1. Personal dose equivalent $H_{\mathrm{p}}(10)$-response, normalised to $\mathrm{Am}-\mathrm{Be}$, as a function of the neutron energy (• measured, - calculated).

Table 1 shows the measured personal dose equivalent $H_{\mathrm{p}}(10)$-responses for an irradiation on the front surface of the phantom, the measured PE/ $\mathrm{PE}(\mathrm{Li})$ ratios and the detection limits. The automatic readout system is capable of distinguishing between the tracks behind the $\mathrm{PE}$ and $\mathrm{PE}(\mathrm{Li})$ radiators and can therefore determine the $\mathrm{PE} / \mathrm{PE}(\mathrm{Li})$ ratio. This ratio approaches 1 for spectra with a high fraction of fast- and high-energy neutrons and is equal to 0 for a spectrum with only thermal neutrons. For mixed spectra, the ratio is somewhere in between 1 and 0 . The PADC dosemeters were calibrated with $\mathrm{Am}-\mathrm{Be}$.

Reference values for the ambient neutron dose equivalent $H^{*}(10)_{\text {BSS }}$ were determined with a Bonner sphere spectrometry system $\mathrm{BSS}^{(8)}$. By multiplying $H^{*}(10)_{\mathrm{BSS}}$ with the ratio $H_{\mathrm{p}}(10) / H^{*}(10)^{(8)}$ of personal to ambient neutron dose equivalent, which was determined with a novel directional spectrometry system $\mathrm{DS}^{(8)}$, a value for the personal neutron dose equivalent $H_{\mathrm{p}}(10)_{\mathrm{DS}}$ can be calculated. The $H_{\mathrm{p}}(10)$-responses are the ratio of the measured

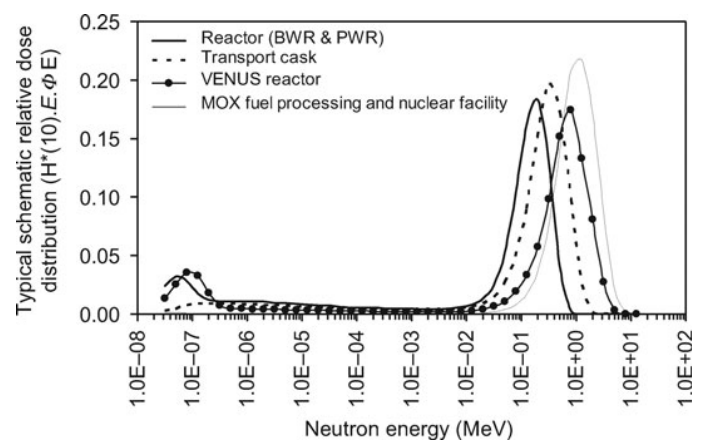

Figure 2. Typical schematic relative dose distribution for real workplace fields ${ }^{(8)}$ of the nuclear industry (ambient dose equivalent distribution plotted against neutron energy) personal dose equivalents to $H_{\mathrm{p}}(10)_{\text {DS }}$. In Figure 3, the measured $H_{\mathrm{p}}(10)$-responses for all spectra are presented.

In some cases, the neutron dose was too low to be measured by the PADC personal neutron dosemeter; therefore, the responses are estimated for all spectra by convoluting the fitted response of measured and calculated responses to monoenergetic neutrons for an angle of incidence of $0^{\circ}$ with the $H^{*}(10)_{\text {BSS }}^{(8)}$ dose energy distribution measured within EVIDOS. The estimation delivers only responses with high uncertainties because the angular dependence of the neutron response is not considered. Apart from the EVIDOS project, also $H^{*}(10)$-responses to nuclear power plant spectra in Switzerland were estimated. Four different measured types of spectra $^{(9)}$ were used: very soft (type A, mostly thermal neutrons) through to very hard dose spectra (type D) with maximum neutron energies of $10 \mathrm{MeV}$ and peak energies of $\sim 0.1-1 \mathrm{MeV}$. Table 2 shows the measured and estimated $H^{*}(10)$-responses, the estimated $\mathrm{PE} / \mathrm{PE}(\mathrm{Li})$ ratios and detection limits. The measured $H^{*}(10)$-responses are calculated by dividing the measured $H_{\mathrm{p}}(10)$-dose values with the $H^{*}(10)_{\mathrm{BSS}}^{(8)}$ neutron dose equivalent.

The detection limits are calculated with the assumption that PADC detectors of good quality are used (single standard deviation of background detectors up to $5 \mathrm{~cm}^{-2}$ and a sensitivity to $\mathrm{Am}-\mathrm{Be}$ of $170 \mathrm{mSv}^{-1} / \mathrm{cm}^{-2}$ ). The detection limit is calculated by dividing the triple standard deviation of the background detectors with the sensitivity to $\mathrm{Am}-\mathrm{Be}$ and the measured/estimated response to the field spectrum.

In Figure 4, the measured and estimated responses to simulated and real workplace fields of the nuclear industry, normalised to $\mathrm{Am}-\mathrm{Be}$, are presented relative to the $\mathrm{PE} / \mathrm{PE}(\mathrm{Li})$ ratio.

\section{DISCUSSION AND CONCLUSION}

The comparison of measured and estimated $H^{*}(10)$ responses of Table 2 shows that in most cases the estimated $H^{*}(10)$-responses are higher than the measured $H^{*}(10)$-responses (with the exception of CASK TN $\mathrm{N})$. However, it is expected that the estimated values are higher because the angular distribution of neutrons in the workplace field and the angular dependence of the dosemeter is neglected.

The measured $H_{\mathrm{p}}(10)$-responses vary between 0.3 and 1.4, depending on the spectrum. The average $H_{\mathrm{p}}(10)$-response over all measured spectra is $0.85 \pm$ 0.33 . If it is unknown in what workplace field the dosemeter was used, it is recommended to use this average response as a correction factor. To use the $\mathrm{PE} / \mathrm{PE}(\mathrm{Li})$ ratio is only administrable when the neutron spectrum is highly thermalised and a higher response should be used. 
Table 1. Reference values for $H_{\mathrm{p}}(10)$, measured $H_{\mathrm{p}}(10)$-responses, normalised to $\mathrm{Am}-\mathrm{Be}$ and measured PE/PE(Li) ratios for the PADC dosemeter and detection limits for various locations.

\begin{tabular}{|c|c|c|c|c|}
\hline $\begin{array}{l}\text { Measurement } \\
\text { position }\end{array}$ & $\begin{array}{c}\text { Reference } \\
H_{\mathrm{p}}(10)_{\mathrm{DS}}^{(8)}(\mathrm{mSv})\end{array}$ & $\begin{array}{c}\text { Measured response } \\
H_{\mathrm{p}}(10) / H_{\mathrm{p}}(10)_{\mathrm{DS}}^{(8)}\end{array}$ & $\begin{array}{c}\text { Measured ratio } \\
\mathrm{PE} / \mathrm{PE}(\mathrm{Li})\end{array}$ & $\begin{array}{l}\text { Detection limit } \\
(\mathrm{mSv})\end{array}$ \\
\hline SIGMA & 1.84 & $0.51 \pm 0.16$ & $0.83 \pm 0.10$ & 0.20 \\
\hline CANEL & 1.50 & $0.33 \pm 0.04$ & $0.85 \pm 0.25$ & 0.25 \\
\hline BWR SAR & 0.40 & $*$ & $*$ & * \\
\hline BWR T & 0.10 & * & * & * \\
\hline PWR L & 1.74 & $0.82 \pm 0.27$ & $0.20 \pm 0.10$ & 0.10 \\
\hline PWR A & 2.33 & $1.36 \pm 0.50$ & $0.40 \pm 0.10$ & 0.10 \\
\hline VENUS F & 0.15 & $1.03 \pm 0.34$ & $* * *$ & 0.10 \\
\hline VENUS C & $* *$ & $* *$ & $* *$ & $* *$ \\
\hline Cask NTL M & 0.42 & $0.43 \pm 0.36$ & $* * *$ & 0.20 \\
\hline Cask NTL S & 0.14 & $*-0.00$ & * & $*$ \\
\hline Cask TN D & 0.42 & $0.70 \pm 0.30$ & $* * *$ & 0.15 \\
\hline Cask TN N & 0.15 & $1.37 \pm 0.81$ & $* * *$ & 0.10 \\
\hline $\mathrm{BN} 1$ & 0.61 & $1.11 \pm 0.48$ & $* * *$ & 0.10 \\
\hline $\mathrm{BN} 2 \mathrm{~A}$ & 1.96 & $0.68 \pm 0.22$ & $0.91 \pm 0.15$ & 0.15 \\
\hline BN 2B & 0.25 & $1.28 \pm 0.44$ & $* * *$ & 0.10 \\
\hline BN 3 & 0.35 & $0.87 \pm 0.29$ & $* * *$ & 0.10 \\
\hline NF 1 & 5.56 & $0.75 \pm 0.24$ & 0.870 .13 & 0.15 \\
\hline NF 2 & 0.65 & $0.71 \pm 0.27$ & $* * *$ & 0.15 \\
\hline NF 3 & $* *$ & $* *$ & $* *$ & $* *$ \\
\hline
\end{tabular}

*Dosemeter signal below or equal background signal.

${ }_{* * * *}^{* *}$ Not measured.

**** Track density too low to calculate the PE/PE(Li) ratio.

The detection limits vary between 0.1 and $0.3 \mathrm{mSv}$, implying PADC detectors with good quality. The most critical part is the homogeneity of the detector material (to obtain a low standard deviation of the background detectors).

Summarising, it can be said that the PADC dosemeter is suited for the use in neutron spectra predominated by a thermal or fast component, e.g. for MOX fuel processing spectra and VENUS reactor spectra. For reactor and transport cask

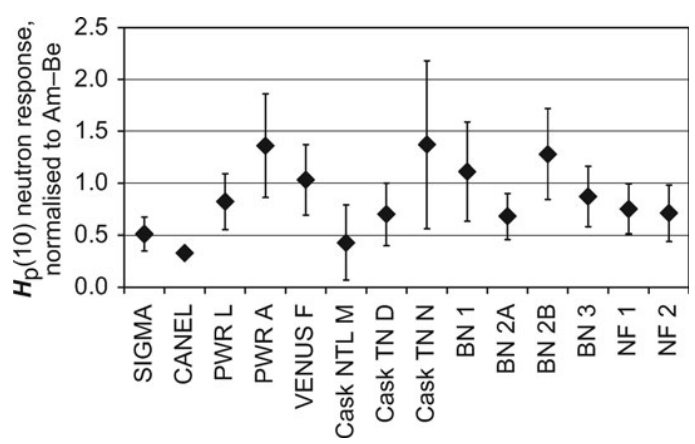

Figure 3. Personal dose equivalent $\left(H_{\mathrm{p}}(10)\right)$ response measured with PADC dosemeter and normalised to Am-Be. spectra predominated by neutron energies $<1 \mathrm{MeV}$, the PADC dosemeter is not recommended.

\section{ACKNOWLEDGEMENTS}

This work was partly performed in the framework of EC contract FIRK-CT-2001-00175 and was partly financed by the Federal Office of Education and Science (BBW contract No. 01.0024).

\section{REFERENCES}

1. d'Errico, F. et al. Evaluation of Individual Dosimetry in Mixed Neutron and Photon Radiation Fields (EVIDOS). Part I: Scope and methods of the project. IM2005 European workshop on individual monitoring of ionising radiation, Vienna, Austria, 11-15 April 2005. To be published.

2. Fiechtner, A. and Wernli, C. Individual neutron monitoring with CR-39 at an accelerator centre. Radiat. Prot. Dosim. 85(1-4), 35-38 (1999).

3. Fiechtner, A., Boschung, M. and Wernli C. Progress report of the CR39-neutron personal monitoring service at PSI. Radiat. Prot. Dosim. 2006; doi: 10.1093/rpd/ ncl114.

4. Alsmiller, R. G. Jr. and Barish, J. The calculated response of ${ }^{6} \mathrm{LiF}$ albedo dosimeters to neutrons with energies $\leq 400 \mathrm{MeV}$. Health Phys. 26(1), 13-28 (1974). 
Table 2. Measured and estimated $H^{*}(10)$-responses, normalised to Am-Be, estimated PE/PE(Li) ratios and estimated detection limits for various locations.

\begin{tabular}{|c|c|c|c|c|}
\hline $\begin{array}{l}\text { Measurement } \\
\text { position }\end{array}$ & $\begin{array}{c}\text { Measured } H^{*}(10) \text {-response } \\
H_{\mathrm{p}}(10) / H^{*}(10)_{\mathrm{BBS}}^{(8)}\end{array}$ & $\begin{array}{c}\text { Estimated } \\
H^{*}(10) \text {-response }\end{array}$ & $\begin{array}{l}\text { Estimated ratio } \\
\mathrm{PE} / \mathrm{PE}(\mathrm{Li})\end{array}$ & $\begin{array}{l}\text { Estimated detection } \\
\text { limit }(\mathrm{mSv})\end{array}$ \\
\hline SIGMA & $0.55 \pm 0.17$ & - & - & - \\
\hline CANEL & $0.28 \pm 0.03$ & - & - & - \\
\hline BWR SAR & $*$ & $0.3 \pm 0.1$ & $0.8 \pm 0.1$ & 0.30 \\
\hline BWR T & $*$ & $0.3 \pm 0.1$ & $0.8 \pm 0.1$ & 0.30 \\
\hline PWR L & $0.38 \pm 0.13$ & $0.3 \pm 0.1$ & $0.8 \pm 0.1$ & 0.30 \\
\hline PWR A & $0.45 \pm 0.17$ & $0.3 \pm 0.1$ & $0.7 \pm 0.1$ & 0.30 \\
\hline VENUS F & $0.41 \pm 0.14$ & $0.7 \pm 0.1$ & $0.9 \pm 0.1$ & 0.15 \\
\hline VENUS C & $* *$ & $0.8 \pm 0.1$ & $0.9 \pm 0.1$ & 0.10 \\
\hline Cask NTL M & $0.30 \pm 0.25$ & $0.6 \pm 0.1$ & $1.0 \pm 0.1$ & 0.15 \\
\hline Cask NTL S & $*-$ & $0.6 \pm 0.1$ & $1.0 \pm 0.1$ & 0.15 \\
\hline Cask TN D & $0.51 \pm 0.22$ & $0.5 \pm 0.1$ & $0.9 \pm 0.1$ & 0.20 \\
\hline Cask TN N & $0.85 \pm 0.50$ & $0.4 \pm 0.1$ & $0.8 \pm 0.1$ & 0.20 \\
\hline BN 1 & $0.63 \pm 0.27$ & $1.0 \pm 0.1$ & $1.0 \pm 0.1$ & 0.10 \\
\hline $\mathrm{BN} 2 \mathrm{~A}$ & $0.53 \pm 0.17$ & $1.0 \pm 0.1$ & $1.0 \pm 0.1$ & 0.10 \\
\hline $\mathrm{BN} 2 \mathrm{~B}$ & $0.82 \pm 0.28$ & $0.8 \pm 0.1$ & $1.0 \pm 0.1$ & 0.10 \\
\hline $\mathrm{BN} 3$ & $0.47 \pm 0.16$ & $0.8 \pm 0.1$ & $1.0 \pm 0.1$ & 0.10 \\
\hline NF 1 & $0.45 \pm 0.14$ & $0.8 \pm 0.1$ & $1.0 \pm 0.1$ & 0.10 \\
\hline NF 2 & $0.29 \pm 0.11$ & $0.7 \pm 0.1$ & $0.9 \pm 0.1$ & 0.15 \\
\hline NF 3 & $* *$ & $0.9 \pm 0.1$ & $1.0 \pm 0.1$ & 0.10 \\
\hline Type A (soft) $)^{(9)}$ & $* *$ & $0.45 \pm 0.10^{\mathrm{a}}$ & $0.2 \pm 0.1$ & 0.20 \\
\hline Type $\mathrm{B}^{(9)}$ & $* *$ & $0.40 \pm 0.10^{\mathrm{a}}$ & $0.8 \pm 0.1$ & 0.20 \\
\hline Type $C^{(9)}$ & $* *$ & $0.50 \pm 0.10^{\mathrm{a}}$ & $1.0 \pm 0.1$ & 0.20 \\
\hline Type D (hard) ${ }^{(9)}$ & $* *$ & $1.05 \pm 0.20^{\mathrm{a}}$ & $1.0 \pm 0.1$ & 0.10 \\
\hline
\end{tabular}

${ }^{*}$ Dosemeter signal below or equal background signal.

N** measured.

${ }^{\mathrm{a}}$ Reference values $H^{*}(10)$ from elsewhere ${ }^{(9)}$.

For comparison reasons the relative responses to $H^{*}(10)_{\mathrm{BSS}}^{(8)}$ are used.

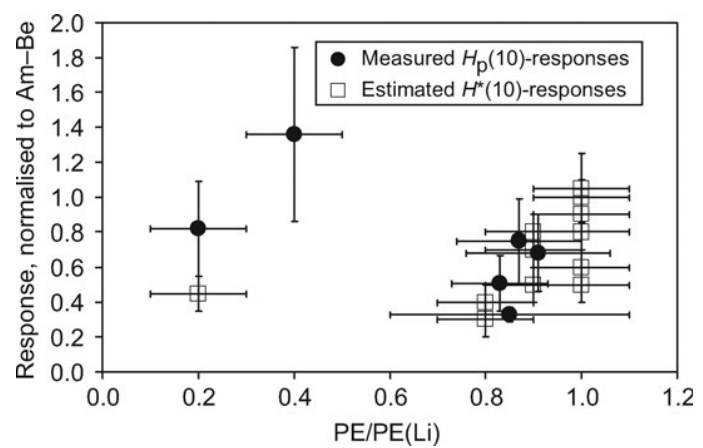

Figure 4. Measured and estimated responses to simulated and real workplace fields of the nuclear industry relative to the $\mathrm{PE} / \mathrm{PE}(\mathrm{Li})$ ratio.
5. McLane, V., Dunford, C. L. and Rose, P. F. Neutron Cross Sections. Vol. 2 (Academic Press, Inc.) (1988).

6. Gressier, V. et al. Characterization of the IRSN CANEL/T400 facility producing realistic neutron fields for calibration and test purposes. Radiat. Prot. Dosim. 110(1-4), 523-527 (2004).

7. Lacoste, V., Gressier, V., Muller, H. and Lebreton L. Characterization of the IRSN Graphite moderated americium-beryllium neutron field. Radiat. Prot. Dosim. 110(1-4), 135-139 (2004).

8. Schuhmacher, H. et al. Evaluation of individual dosimetry in mixed neutron and photon radiation fields. PTB-N-49, March (2006), ISBN 3-86509-503-8

9. Aroua, A. et al. Characterisation of the Mixed neutrongamma fields inside the Swiss nuclear power plants by different active systems. Radiat. Prot. Dosim. 51(1), $17-25$ (1994). 